\title{
Geometrical Analysis of the Thermal Conductivity of Nanofluids Using Different Models
}

\author{
Mohammed Nizam Uddin ${ }^{1}$, A. N. M. Rezaul Karim,", Jannatul Naime ${ }^{1}$, Masud Rana ${ }^{1}$ \\ ${ }^{1}$ Department of Applied Mathematics, Noakhali Science and Technology University, Noakhali, Bangladesh. \\ ${ }^{2}$ Department of Computer Science \& Engineering, International Islamic University Chittagong, Chittagong, Bangladesh.
}

How to cite this paper: Mohammed $\mathrm{Ni}-$ zam Uddin, A. N. M. Rezaul Karim, Jannatul Naime, Masud Rana. (2021) Geometrical Analysis of the Thermal Conductivity of Nanofluids Using Different Models. Journal of Applied Mathematics and Computation, 5(3), 207-218.

DOI: 10.26855/jamc.2021.09.007

Received: August 9, 2021

Accepted: September 5, 2021

Published: September 16, 2021

*Corresponding author: A. N. M. Rezaul Karim, Department of Computer Science \& Engineering, International Islamic University Chittagong, Chittagong, Bangladesh.

Email: zakianaser@yahoo.com

\begin{abstract}
Nanofluids (NF) have recently emerged as pioneers of standard heat transfer fluid augmentation or potential replacement. The potential for NFs to be employed in a wide range of technical applications, ranging from renewable energy to nanomedicine, have become one of today's most investigated issues. The widespread use of warmth to move liquids in modern applications emphasizes their critical role in the effectiveness of the system. The various methods for determining the thermal conductivity of NFs are explained. Using hypothetical thermal conductivity (TC) models like Hamilton and Crosser, Jeffrey, Maxwell, Davis, and Bruggeman, the heat conductivity of Water, Liquid Sodium, and Ethylene Glycol possessing unique concentrations for Copper, Aluminum and Silver nanoparticles are investigated in this study. As a result, this study provides an overview of the most significant achievements and contentious discoveries in the field of NFs thermal conductivity. The findings reveal that when nanoparticles are fixed, the thermal conductivity of nanofluids increases.
\end{abstract}

\section{Keywords}

Thermal Conductivity, Nanoparticles, Nanofluids, Maxwell model, Suresh and Davis models, Bruggeman model

\section{Introduction}

Nanofluids are a fresh type of homogeneous mixtures of low-centralization nanoparticles and common liquids/oils created for dramatically enhancing their warm and hostile to wear execution [1]. The millimeter-scaled molecule scatterings have a number of drawbacks, including sedimentation, part disintegration, clogging, and unwanted pressing factor drop, all of which can be avoided by using nanofluids, which are created by uniformly scattering nanoparticles.

By avoiding basic concerns such as obstructions, precipitation, and disintegration, nanoparticles have a simple fluidized measure. By avoiding basic concerns such as obstructions, precipitation, and disintegration, nanoparticles have a fluidized measure that is simple [2] [3]. The TC of the regular working liquid of warmth transmission frameworks is thought to be an important factor in increasing the efficiency of heat transfer. A lot of scientists have recently claimed that the TC of nanofluid has improved as a result of trial concentrating [4]. The TC was examined by Duangthongsuk et al. and consistency of Titanium dioxide nanoparticles centralizations ranging from 0.2 to 2 microns. The findings reveal that as the volume concentration of nanoparticles raises, so does the TC of nanofluids and falls as the temperature rises [5]. Sharp edges, platelets, round and hollow, blocks, and circular form nanoparticles were studied by Alawi et al. to see how they affected the TC of metallic oxide nanofluids. The best warmth transfer enhancement is found in nanofluids containing spherical nanoparticles, next came barrel-shaped nanoparticles, blocks, sharp edges, and platelets shapes, in that order [6]. One study found that the heat conductivity of a graphene oxide-based nanofluid made of deionized water and ethy- 
lene glycol and a weight component for $0.10 \%$ and a temperature of $25^{\circ} \mathrm{C}-45^{\circ} \mathrm{C}$ resulted in a $6.67-10.47 \%$ improvement [7]. The heat conductivity of carbon nano tube-polyalpha Olefin oil nanofluid of percentage of $1 \%$ was investigated by Choi et al. and it was also discovered a TC improvement of $160 \%$.

Another study found that the heat conductivity of Poly Ethylene Glycol on CuO Nanoparticles-fluid having a proportion of $4 \%$ and found a $20 \%$ improvement in heat conductivity [8].

Aluminum, Silver, and Copper nanoparticles have thermal conductivities of $237 \mathrm{~W} / \mathrm{mK}, 429 \mathrm{~W} / \mathrm{mK}$, and $400 \mathrm{~W} / \mathrm{mK}$, in that order, while Water, Ethylene glycol, and Liquid Sodium have thermal conductivities of $0.605 \mathrm{~W} / \mathrm{mK}, 0.252 \mathrm{~W} / \mathrm{mK}$, and $76 \mathrm{~W} / \mathrm{mK}$, in that order [9] [10].

The heat conductivity of Ethylene glycol, Water and Liquid Sodium possessing different centralizations of Aluminum, Silver, and Copper nanoparticles is evaluated in this study by theoretical and observational TC model as an example Maxwell model and the findings are presented and debated [11].

\section{Nano Fluids Preparation}

The main step in the nanofluids test investigations is to arrange the nanofluids. Both the one-step and two-step preparation processes are both important methodologies for nanofluid planning. The following is a brief discussion of the nanofluid preparation method.

Single-step preparation process: The one-step preparation procedure displays the single-step mixing of nanofluids. For nanofluid arrangement, a few single-step approaches have been demonstrated. Akoh et al. developed a single direct advance dissipation approach [12]. VEROS (Vacuum Evaporation onto a Running Oil Substrate) is the name of this cycle. Regardless, isolating nano-particles from liquid structures was difficult. Eastman et al. created a customized VEROS process in which $\mathrm{Cu}$ fume is densely packed into nanoparticles by contacting it with low-fume-pressure ethylene glycol in a stream by reducing copper sulphate. $5 \mathrm{H}_{2} \mathrm{O}$ with $\mathrm{NaH}_{2} \mathrm{PO}_{2} \cdot \mathrm{H}_{2} \mathrm{O}$ in ethylene glycol under microwave illumination, Zhu et al. developed a single advanced chemical interaction for the design of $\mathrm{Cu}$ nanofluids [13]. This technology also works well for delivering silver nanofluids that are based on mineral oil. To create Copper oxide, $\mathrm{Cu}_{2} \mathrm{O}$. and $\mathrm{Cu}$ based nanofluids with various dielectric fluids, Lo et al. created a vacuum-based decreased circular segment nano-particle combination. To supply an electric circular segment between 6,000 and $12,000^{\circ} \mathrm{C}$, which liquefies and disintegrates a metal pole in the area where the curve is produced, a suitable force source is required. The disintegrating metal is dense, and deionized water scatters it to generate nanofluids. [14]. The one-venture blend process has the advantage of limiting nano-particle aggregation. The main challenge is that such a cycle is only practicable with lone low fume pressure liquids. Figure 1 shows a one-venture planning measure (substance interaction) for nanofluids.

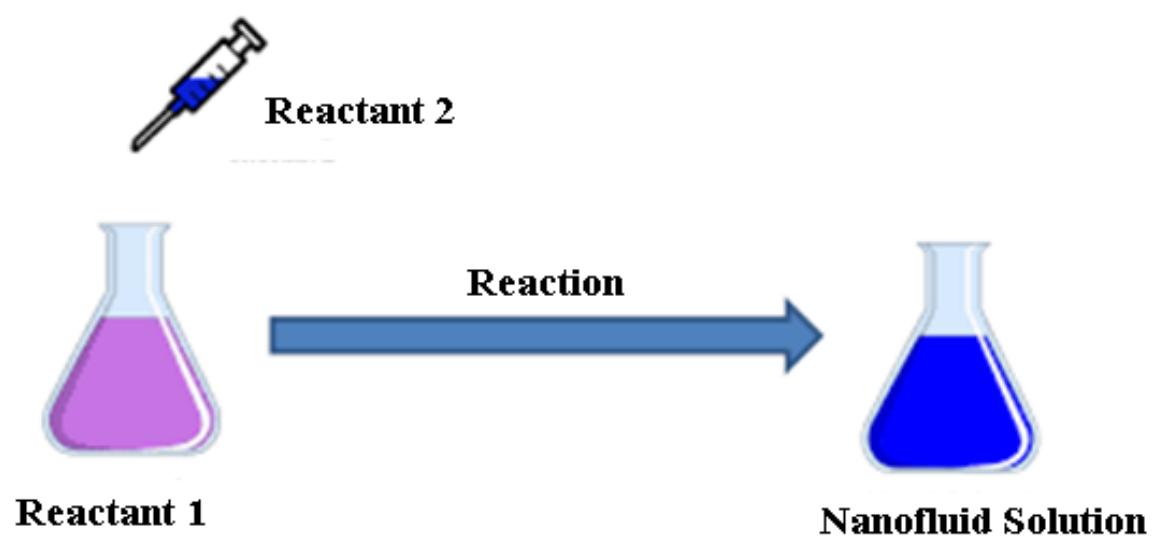

Figure 1. Single-step Preparation Process of nanofluids.

Two-step preparation process: By combining base liquids with economically accessible nanoparticles obtained through various mechanical, physical, and material courses like processing, crushing, and sol-gel and fume stage techniques, the two-step preparation procedure is widely employed in the blend of nano-fluids. Mixing Nano particles with liquids is usually done with an ultrasonic vibrator or a higher shear blending device. To reduce molecular agglomeration, it is necessary to use ultrasonication or blending multiple times.

Murshed et al. used a similar technique to arrange TiO 2-water Nano suspension [15]. Xuan et al. developed nanofluids of both water and transformer oil using commercially available $\mathrm{Cu}$ nanoparticles. Kim et al. made an application of a 
two-step technique to create $\mathrm{CuO}$ dispersed ethylene glycol nanofluids without stabilizers using a two-step strategy. Union of carbon nanotube-based nanofluids can also be accomplished via a two-step method. Pyrolysis is used to release single-walled and multi-walled carbon nano-tubes, which are then balanced in base liquids with or without the usage of surfactants [16] [17]. A few authors suggested that preparing nanofluids including oxide nanoparticles in two steps is more reasonable than preparing nanofluids containing metallic nanoparticles in one stage. As the powders effectively total due to solid vander Walls power among nanoparticles, consistency is a big challenge that fundamentally identified with this activity. Despite these drawbacks, this cycle is still widely used as the most profitable method of producing nanofluids. Figure 2 depicts the most well-known two-step method [18].

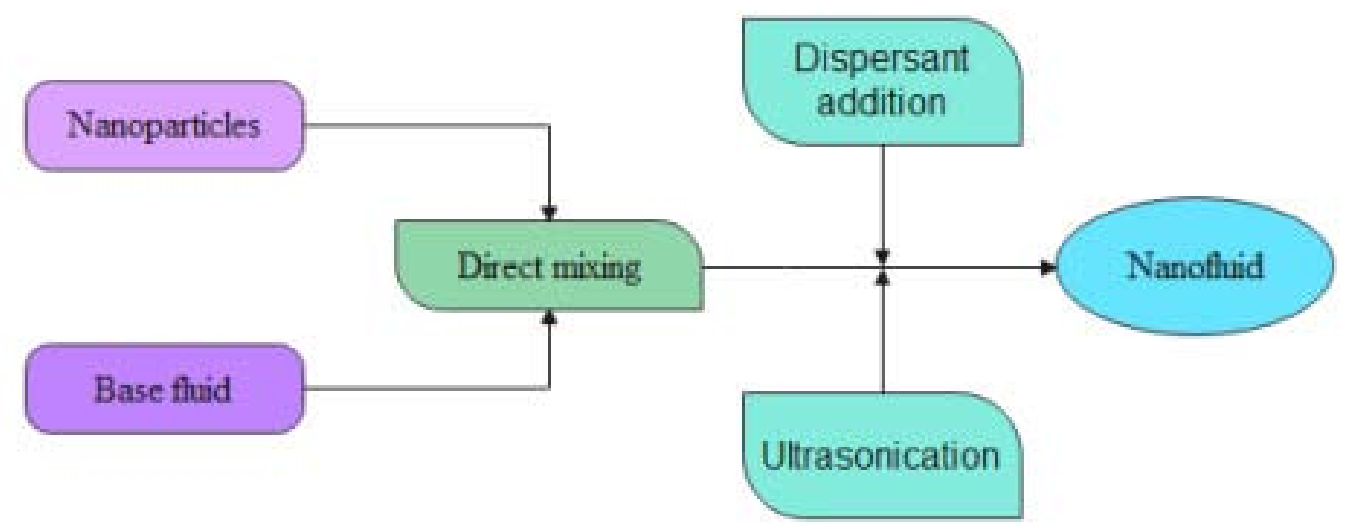

Figure 2. Two-step preparation process of nanofluids.

\section{Thermal Conductivity of Nanofluids}

To predict the successful TC of nanofluids, a variety of speculative and specific forms have been presented. To estimate the heat conductivity of blends and composites, the most prominent models such as Effective Medium Theory and the Maxwell model (Equation 1) are usually utilized [19]. Molecule scattering is acknowledged in the Maxwell heat conductivity model for the low molecule volume region of round nanoparticles. Collaborations between particles, nano particle size, and the temperature of the base liquid are ruled out.

$$
\frac{k_{\text {eff }}}{k_{f}}=\frac{k_{p}+2 k_{f}+2 \varphi\left(k_{p}-k_{f}\right)}{k_{p}+2 k_{f}-\varphi\left(k_{p}-k_{f}\right)}
$$

The Shape aspect is important in determining the powerful heat conductivity of liquid including round, and hollow nanoparticles, is used to develop the Hamilton and Crosser (Equation 2) model. Where n relies upon molecule shape and $\frac{\mathrm{K}_{\mathrm{s}}}{\mathrm{K}_{1}}, \mathrm{n}=\frac{3}{\varphi}$ for $\frac{\mathrm{K}_{\mathrm{s}}}{\mathrm{K}_{1}}>100, \mathrm{n}=3$ for different cases. By considering the architecture and condition of nanoparticles, the compelling TC of both consistent and spasmodic stages is determined using this approach [20].

The Maxwell, Hamilton, and Crosser models were modified to create the majority of additional static TC models [21].

$$
\frac{\mathrm{k}_{\mathrm{eff}}}{\mathrm{k}_{\mathrm{f}}}=\frac{\mathrm{k}_{\mathrm{p}}+(\mathrm{n}-1) \mathrm{k}_{\mathrm{f}}-(\mathrm{n}-1) \varphi\left(\mathrm{k}_{\mathrm{f}}-\mathrm{k}_{\mathrm{p}}\right)}{\mathrm{k}_{\mathrm{p}}+(\mathrm{n}-1) \mathrm{k}_{\mathrm{f}}+\varphi\left(\mathrm{k}_{\mathrm{f}}-\mathrm{k}_{\mathrm{p}}\right)}
$$

To anticipate the compelling thermal conductivity, the Jeffrey model (Equation 3) was devised by considering the collaboration between two haphazardly spread nanoparticles in a liquid medium [22].

$$
\frac{\mathrm{k}_{\text {eff }}}{\mathrm{k}_{\mathrm{m}}}=1+3 \beta v+\left(3 \beta^{2}+\frac{3 \beta^{2}}{4}+\quad \frac{9 \beta^{3}}{16} \frac{\alpha+2}{2 \alpha+3}+\cdots \cdots\right) v^{2}
$$

In the Davis model, connection of distributed circular in the liquid environment is addressed for measuring the TC of nanofluids, similar to Jeffrey's TC model, which has large request terms due to pair communications of haphazardly spread circles [23].

$$
\frac{\mathrm{k}_{\mathrm{eff}}}{\mathrm{k}_{\mathrm{f}}}=1+\frac{3(\alpha-1) \varphi}{(\alpha+2)-(\alpha-1) \varphi}\left[\varphi+\mathrm{f}(\alpha) \varphi^{2}+\quad 0(\varphi)^{3}\right]
$$

The model Bruggeman (from equation no 5) is utilized to foresee the viable TC of the parallel combination of uniform round and arbitrarily scattered nanoparticles [24]. 


$$
\frac{\mathrm{k}_{\text {eff }}}{\mathrm{k}_{\mathrm{f}}}=\frac{1}{4}\left[(3 \varphi-1) \frac{\mathrm{k}_{\mathrm{p}}}{\mathrm{k}_{\mathrm{f}}}+(2-3 \varphi)+\frac{\mathrm{k}_{\mathrm{f}}}{4} \sqrt{\Delta}\right]
$$

where,

$\mathrm{k}_{\text {eff }}$ is the effective TC of nanoparticles $(\mathrm{W} / \mathrm{mk})$

$\mathrm{k}_{\mathrm{f}}$ is the TC of base fluids (W/mk)

$\mathrm{k}_{\mathrm{p}}$ is the TC of the particle

$\varphi$ is the volume fraction of the particles, $\mathrm{n}$ is the empirical shape factor given by $\mathrm{n}=\frac{3}{\varphi}$, and $\varphi$ is the sphericity. For spherical and cylindrical particles, the values of sphericity $(\varphi)$ are 1 and 0.5 respectively.

The TC of nanoparticles at rates ranging from one to eight is determined using the methodology in Equations 1-5 [25] [26]. The TC of ethylene glycol, water, and liquid sodium possessing silver, aluminum and copper is presented separately in the tables below.

Table 1 shows the TC of water possessing 1-8 percent aluminum nanoparticles, as well as an analysis of the consequences by hypothetical TC models [27].

Table 1. TC of nanofluids (Water + Aluminum)

\begin{tabular}{|c|c|c|c|c|c|}
\hline $\begin{array}{c}\text { Nano } \\
\text { Particle } \\
\text { Percentage } \\
\text { and } \\
\text { Crosser } \\
\text { Model }\end{array}$ & $\begin{array}{c}\text { Hamilton } \\
\text { Model }\end{array}$ & $\begin{array}{c}\text { Maxwell } \\
\text { Model }\end{array}$ & $\begin{array}{c}\text { Davis } \\
\text { Model }\end{array}$ & $\begin{array}{c}\text { Bruggeman } \\
\text { Model }\end{array}$ \\
\hline 1 & 0.6231 & 0.6222 & 0.6238 & 0.6218 & 0.6218 \\
\hline 2 & 0.6456 & 0.6434 & 0.6318 & 0.6478 & 0.6372 \\
\hline 3 & 0.6628 & 0.6658 & 0.6564 & 0.6634 & 0.6608 \\
\hline 4 & 0.6800 & 0.6864 & 0.6810 & 0.6812 & 0.6814 \\
\hline 5 & 0.6917 & 0.6991 & 0.6998 & 0.7074 & 0.7028 \\
\hline 6 & 0.7049 & 0.7194 & 0.7113 & 0.7304 & 0.7487 \\
\hline 7 & 0.7224 & 0.7288 & 0.7229 & 0.7663 & 0.7845 \\
\hline 8 & 0.7436 & 0.7476 & 0.7436 & 0.7916 & 0.8257 \\
\hline
\end{tabular}

At room temperature, aluminum nanoparticles have a TC of $237 \mathrm{~W} / \mathrm{mK}$, while water has a TC of $0.605 \mathrm{~W} / \mathrm{Mk}$ [28].

Water's TC when aluminum nanoparticles are used as a component of the nanoparticle fixation between $1 \%$ and $8 \%$ is shown in Table 1 . The TC of aluminum nanofluids rises linearly as the nanoparticle focus increases. The TC of the nanofluid is improved by taking into account the presence of interfacial layers of nanoparticles according to the interfacial layer concept [29].

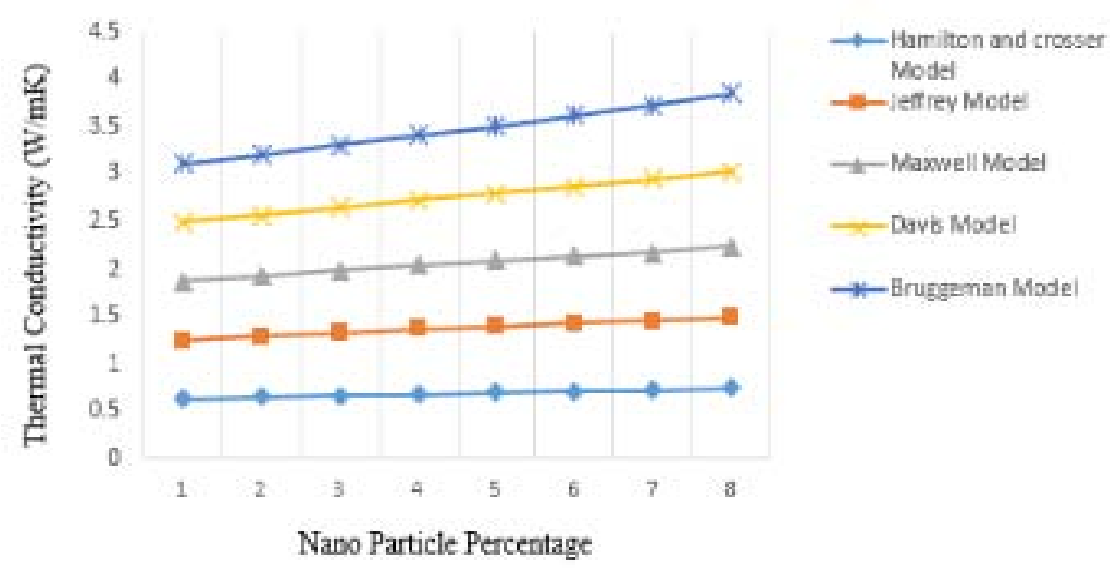

Figure 3. Thermal Conductivity of Nanofluids (Aluminium + Water).

Table 2 shows the TC of water with 1-8 percent silver nanoparticles, as well as the correlation of consequences by hypothetical TC models 
Table 2. TC of nanofluids (Water + Silver)

\begin{tabular}{|c|c|c|c|c|c|}
\hline $\begin{array}{c}\text { Nano } \\
\text { Particle } \\
\text { percentage }\end{array}$ & $\begin{array}{c}\text { Hamilton } \\
\text { and Crosser } \\
\text { Model }\end{array}$ & $\begin{array}{c}\text { Jeffrey } \\
\text { Model }\end{array}$ & $\begin{array}{c}\text { Maxwell } \\
\text { Model }\end{array}$ & $\begin{array}{c}\text { Davis } \\
\text { Model }\end{array}$ & $\begin{array}{c}\text { Bruggeman } \\
\text { Model }\end{array}$ \\
\hline 1 & 0.6231 & 0.6226 & 0.6232 & 0.6224 & 0.6224 \\
\hline 2 & 0.6474 & 0.6492 & 0.6418 & 0.6442 & 0.6418 \\
\hline 3 & 0.6654 & 0.6652 & 0.6574 & 0.6672 & 0.6678 \\
\hline 4 & 0.6802 & 0.6842 & 0.6798 & 0.6884 & 0.6812 \\
\hline 5 & 0.6911 & 0.6955 & 0.7045 & 0.7145 & 0.7034 \\
\hline 6 & 0.7044 & 0.7171 & 0.7158 & 0.7352 & 0.7473 \\
\hline 7 & 0.7290 & 0.7219 & 0.7269 & 0.7778 & 0.7845 \\
\hline 8 & 0.7489 & 0.7427 & 0.7402 & 0.7935 & 0.8219 \\
\hline
\end{tabular}

At room temperature, Silver nano-particles have a TC of $429 \mathrm{~W} / \mathrm{mK}$, whereas Water has a TC of $0.605 \mathrm{~W} / \mathrm{mK}$. Table 2 shows the TC of Silver nano-particle-containing water as a function of nano-particle concentrations ranging from 1 to $8 \%$. Silver nano-fluids' TC rises in a linear relationship with nano-particle concentration [30].

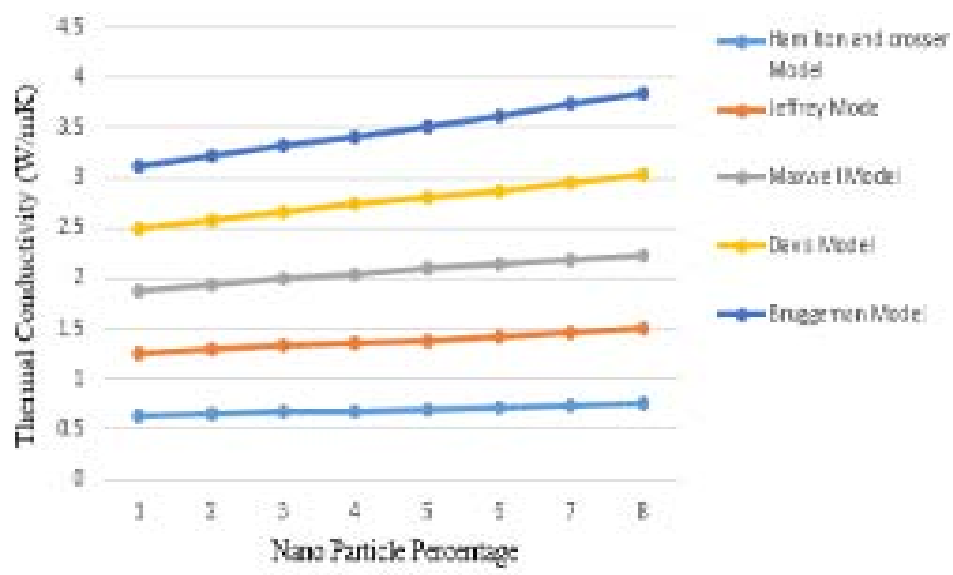

Figure 4. Thermal Conductivity of Nanofluids (Silver + Water).

Table 3 shows the TC of water with 1-8 percent copper nanoparticles, as well as the correlation of consequences by hypothetical TC models [31].

Table 3. TC of nanofluids (Water + Copper)

\begin{tabular}{|c|c|c|c|c|c|}
\hline $\begin{array}{c}\text { Nano } \\
\text { Particle } \\
\text { percentage }\end{array}$ & $\begin{array}{c}\text { Hamilton } \\
\text { and Crosser } \\
\text { Model }\end{array}$ & $\begin{array}{c}\text { Jeffrey } \\
\text { Model }\end{array}$ & $\begin{array}{c}\text { Maxwell } \\
\text { Model }\end{array}$ & $\begin{array}{c}\text { Davis } \\
\text { Model }\end{array}$ & $\begin{array}{c}\text { Bruggeman } \\
\text { Model }\end{array}$ \\
\hline 1 & 0.6217 & 0.6273 & 0.6223 & 0.6210 & 0.6274 \\
\hline 2 & 0.6374 & 0.6438 & 0.6355 & 0.6424 & 0.6356 \\
\hline 3 & 0.6482 & 0.6678 & 0.6472 & 0.6692 & 0.6514 \\
\hline 4 & 0.6552 & 0.6874 & 0.6802 & 0.6856 & 0.6878 \\
\hline 5 & 0.6858 & 0.6998 & 0.7000 & 0.7111 & 0.7187 \\
\hline 6 & 0.7084 & 0.7148 & 0.7158 & 0.7347 & 0.7453 \\
\hline 7 & 0.7267 & 0.7234 & 0.7269 & 0.7714 & 0.7891 \\
\hline 8 & 0.7468 & 0.7411 & 0.7402 & 0.7979 & 0.8211 \\
\hline
\end{tabular}


Copper nanoparticles have a TC of $400 \mathrm{~W} / \mathrm{mK}$, whereas water has a TC of $0.605 \mathrm{~W} / \mathrm{mK}$ at ambient temperature. Water's TC when copper nanoparticles are used as a component of the nanoparticle fixation between $1 \%$ and $8 \%$ is shown in Table 3. With the fixation of nanoparticles, the TC of Copper nanofluids rises linearly.

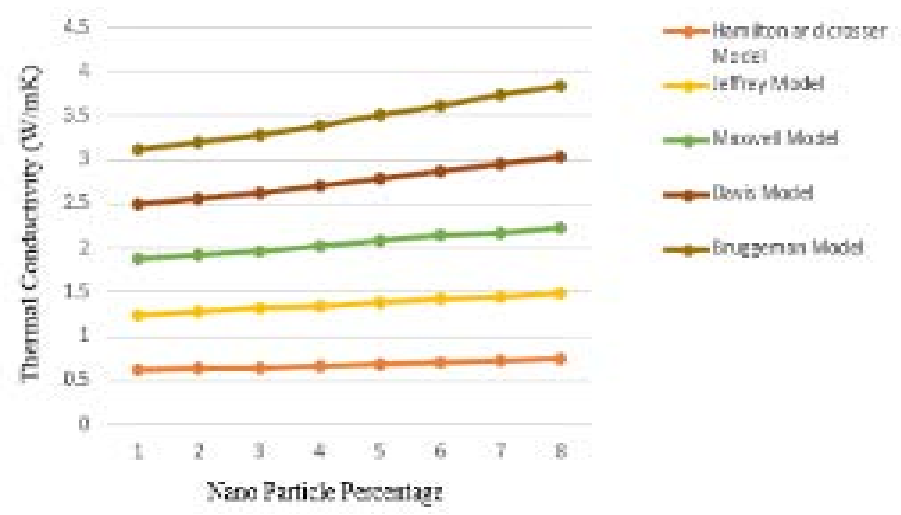

Figure 5. Thermal Conductivity of Nanofluids (Copper + Water).

Table 4 shows the TC of Ethylene glycol with 1-8\% aluminum nanoparticles, as well as a comparison of data obtained using theoretical TC models.

Table 4. TC of nanofluids (Ethylene glycol + Aluminum)

\begin{tabular}{|c|c|c|c|c|c|}
\hline $\begin{array}{c}\text { Nano } \\
\text { Particle } \\
\text { percentage }\end{array}$ & $\begin{array}{c}\text { Hamilton } \\
\text { and Crosser } \\
\text { Model }\end{array}$ & $\begin{array}{c}\text { Jeffrey } \\
\text { Model }\end{array}$ & $\begin{array}{c}\text { Maxwell } \\
\text { Model }\end{array}$ & $\begin{array}{c}\text { Davis } \\
\text { Model }\end{array}$ & $\begin{array}{c}\text { Bruggeman } \\
\text { Model }\end{array}$ \\
\hline 1 & 0.2560 & 0.2534 & 0.2592 & 0.2518 & 0.2542 \\
\hline 2 & 0.2658 & 0.2674 & 0.2644 & 0.2619 & 0.2686 \\
\hline 3 & 0.2774 & 0.2782 & 0.2716 & 0.2734 & 0.2714 \\
\hline 4 & 0.2866 & 0.2814 & 0.2802 & 0.2856 & 0.2828 \\
\hline 5 & 0.2903 & 0.2921 & 0.2911 & 0.2913 & 0.2955 \\
\hline 6 & 0.3078 & 0.3023 & 0.3015 & 0.3165 & 0.3176 \\
\hline 7 & 0.3134 & 0.3145 & 0.3124 & 0.3276 & 0.3386 \\
\hline 8 & 0.3256 & 0.3253 & 0.3254 & 0.3394 & 0.3554 \\
\hline
\end{tabular}

Aluminum nanoparticles have a TC of $237 \mathrm{~W} / \mathrm{mK}$ at ambient temperature, while Ethylene glycol has a TC of 0.252 $\mathrm{W} / \mathrm{mK}$. The TC of Ethylene glycol incorporating aluminum nanoparticles as a component of nanoparticle fixation between $1 \%$ and $8 \%$ is depicted in Table 4 . The TC of aluminum nanofluids increases in direct proportion to the amount of nanoparticles fixed [32].

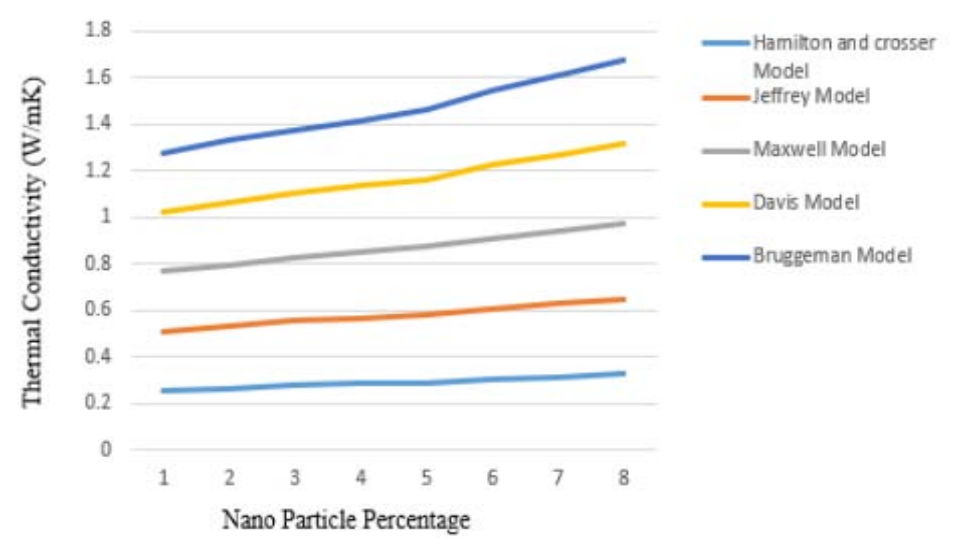

Figure 6. Thermal Conductivity of Nanofluids (Aluminium + Ethylene glycol). 
Table 5 shows the TC of Ethylene glycol with 1-8 percent Silver nanoparticles, as well as the analysis of data using hypothetical TC models [33].

Table 5. TC of nanofluids (Ethylene glycol + Silver)

\begin{tabular}{|c|c|c|c|c|c|}
\hline $\begin{array}{c}\text { Nano } \\
\text { Particle } \\
\text { percentage }\end{array}$ & $\begin{array}{c}\text { Hamilton } \\
\text { and Crosser } \\
\text { Model }\end{array}$ & $\begin{array}{c}\text { Jeffrey } \\
\text { Model }\end{array}$ & $\begin{array}{c}\text { Maxwell } \\
\text { Model }\end{array}$ & $\begin{array}{c}\text { Davis } \\
\text { Model }\end{array}$ & $\begin{array}{c}\text { Bruggeman } \\
\text { Model }\end{array}$ \\
\hline 1 & 0.2546 & 0.2558 & 0.2596 & 0.2578 & 0.2512 \\
\hline 2 & 0.2610 & 0.2694 & 0.2652 & 0.2692 & 0.2632 \\
\hline 3 & 0.2757 & 0.2714 & 0.2718 & 0.2744 & 0.2744 \\
\hline 4 & 0.2812 & 0.2838 & 0.2864 & 0.2872 & 0.2872 \\
\hline 5 & 0.2966 & 0.2967 & 0.2981 & 0.2916 & 0.2911 \\
\hline 6 & 0.3015 & 0.3073 & 0.3077 & 0.3122 & 0.3123 \\
\hline 7 & 0.3119 & 0.3115 & 0.3179 & 0.3232 & 0.3318 \\
\hline 8 & 0.3293 & 0.3222 & 0.3285 & 0.3343 & 0.3535 \\
\hline
\end{tabular}

At normal temperature, Silver nanoparticles have a TC of $429 \mathrm{~W} / \mathrm{mK}$, while Ethylene glycol has a TC of $0.605 \mathrm{~W} / \mathrm{mK}$. In Table 5, the TC of Ethylene glycol with Silver nanoparticles as a component of nanoparticle fixation between 1-8\% is shown. The TC of Silver nanofluids rises in a straight line with the focus of nanoparticles.

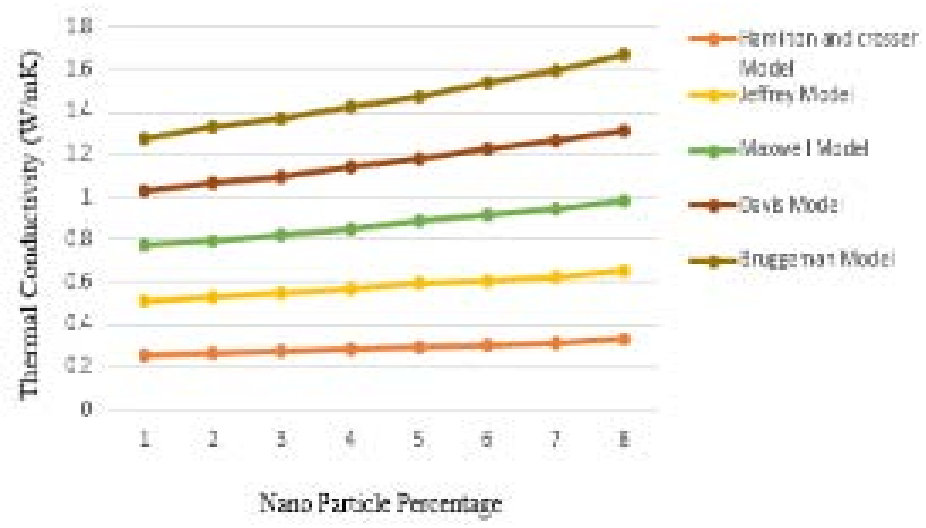

Figure 7. Thermal Conductivity of Nanofluids (Silver+ Ethylene glycol).

The TC of Ethylene glycol with 1-8 percent Copper nanoparticles is shown in Table 6, along with an analysis of the consequences by hypothetical TC models [34].

Table 6. TC of nanofluids (Ethylene glycol + Copper)

\begin{tabular}{|c|c|c|c|c|c|}
\hline $\begin{array}{c}\text { Nano } \\
\text { Particle } \\
\text { percentage }\end{array}$ & $\begin{array}{c}\text { Hamilton } \\
\text { and Crosser } \\
\text { Model }\end{array}$ & $\begin{array}{c}\text { Jeffrey } \\
\text { Model }\end{array}$ & $\begin{array}{c}\text { Maxwell } \\
\text { Model }\end{array}$ & $\begin{array}{c}\text { Davis } \\
\text { Model }\end{array}$ & $\begin{array}{c}\text { Bruggeman } \\
\text { Model }\end{array}$ \\
\hline 1 & 0.2582 & 0.2568 & 0.2594 & 0.2584 & 0.2508 \\
\hline 2 & 0.2644 & 0.2686 & 0.2654 & 0.2618 & 0.2614 \\
\hline 3 & 0.2716 & 0.2732 & 0.2768 & 0.2726 & 0.2738 \\
\hline 4 & 0.2856 & 0.2872 & 0.2882 & 0.2846 & 0.2814 \\
\hline 5 & 0.2991 & 0.2955 & 0.2917 & 0.2936 & 0.2919 \\
\hline 6 & 0.3097 & 0.3067 & 0.3067 & 0.3119 & 0.3138 \\
\hline 7 & 0.3189 & 0.3123 & 0.3108 & 0.3281 & 0.3352 \\
\hline 8 & 0.3278 & 0.3253 & 0.3201 & 0.3367 & 0.3546 \\
\hline
\end{tabular}


Copper nanoparticles have a TC of $400 \mathrm{~W} / \mathrm{mK}$, whereas Ethylene glycol has a TC of $0.252 \mathrm{~W} / \mathrm{mK}$ at ambient temperature. The TC of Ethylene glycol with Copper nanoparticles is depicted in Table 6 as a component of nanoparticle focus in the range of $1-8 \%$. With the fixation of nanoparticles, the TC of Copper nanofluids rises linearly.

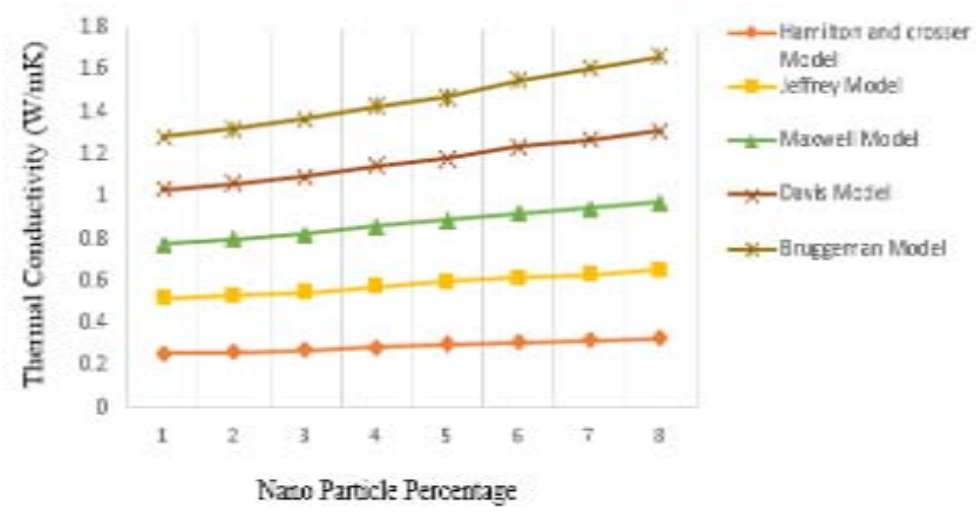

Figure 8. Thermal Conductivity Nanofluids (Copper + Ethylene glycol).

The TC of sodium with 1-8 percent aluminum nanoparticles is provided in Table 7, along with an assessment of outcome by theoretical TC models

Table 7. TC of nanofluids (liquid Sodium + Aluminum)

\begin{tabular}{|c|c|c|c|c|c|}
\hline $\begin{array}{c}\text { Nano } \\
\text { Particle } \\
\text { percentage }\end{array}$ & $\begin{array}{c}\text { Hamilton } \\
\text { and Crosser } \\
\text { Model }\end{array}$ & $\begin{array}{c}\text { Jeffrey } \\
\text { Model }\end{array}$ & $\begin{array}{c}\text { Maxwell } \\
\text { Model }\end{array}$ & $\begin{array}{c}\text { Davis } \\
\text { Model }\end{array}$ & $\begin{array}{c}\text { Bruggeman } \\
\text { Model }\end{array}$ \\
\hline 1 & 76.947 & 78.302 & 76.947 & 76.957 & 73.380 \\
\hline 2 & 77.903 & 79.275 & 77.903 & 77.941 & 74.565 \\
\hline 3 & 78.866 & 80.271 & 78.866 & 78.955 & 75.757 \\
\hline 4 & 79.838 & 81.240 & 79.838 & 79.997 & 76.960 \\
\hline 5 & 80.817 & 82.330 & 80.817 & 81.070 & 78.174 \\
\hline 6 & 81.806 & 83.387 & 81.806 & 82.175 & 79.399 \\
\hline 7 & 82.802 & 84.466 & 82.802 & 83.312 & 80.635 \\
\hline 8 & 83.807 & 85.560 & 83.807 & 84.482 & 81.880 \\
\hline
\end{tabular}

Aluminum nanoparticles have a TC of $237 \mathrm{~W} / \mathrm{mK}$ at ambient temperature, whereas liquid sodium has a TC of 76 $\mathrm{W} / \mathrm{mK}$. Table 7 shows the TC of liquid Sodium with Aluminum nanoparticles as a component of nanoparticle fixation between $1 \%$ and $8 \%$ [35]. The TC of Aluminum nanofluids rises in lockstep with the focus of nanoparticles.

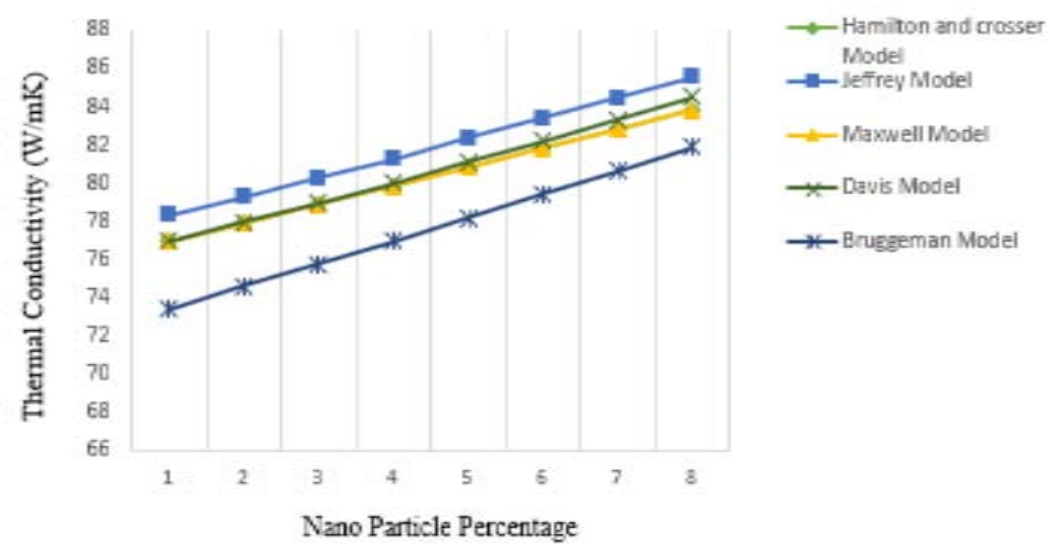

Figure 9. Thermal Conductivity of Nanofluids (Aluminium + Liquid Sodium). 
The TC of sodium with 1-8 percent silver nanoparticles is provided in Table 8, along with an assessment of outcome by theoretical TC models.

Table 8. TC conductivity of nanofluids (Liquid Sodium + Silver)

\begin{tabular}{|c|c|c|c|c|c|}
\hline $\begin{array}{c}\text { Nano } \\
\text { Particle } \\
\text { percentage }\end{array}$ & $\begin{array}{c}\text { Hamilton } \\
\text { and Crosser } \\
\text { Model }\end{array}$ & $\begin{array}{c}\text { Jeffrey } \\
\text { Model }\end{array}$ & $\begin{array}{c}\text { Maxwell } \\
\text { Model }\end{array}$ & $\begin{array}{c}\text { Davis } \\
\text { Model }\end{array}$ & $\begin{array}{c}\text { Bruggeman } \\
\text { Model }\end{array}$ \\
\hline 1 & 76.58798 & 80.18 & 77.39373 & 77.40 & 75.026 \\
\hline 2 & 77.16693 & 81.624 & 78.80461 & 78.86 & 76.598 \\
\hline 3 & 77.73706 & 83.068 & 80.23296 & 80.36 & 78.208 \\
\hline 4 & 78.29857 & 84.588 & 81.67909 & 81.91 & 79.85 \\
\hline 5 & 78.85165 & 86.108 & 83.14334 & 83.51 & 81.549 \\
\hline 6 & 79.39649 & 87.628 & 84.62606 & 85.17 & 83.281 \\
\hline 7 & 89.16223 & 89.604 & 86.1276 & 86.88 & 85.05 \\
\hline 8 & 91.16763 & 90.896 & 87.64831 & 88.65 & 86.872 \\
\hline
\end{tabular}

Silver nanoparticles have a TC of $429 \mathrm{~W} / \mathrm{mK}$ at ambient temperature, while liquid sodium has a TC of $76 \mathrm{~W} / \mathrm{mK}$. Table 8 shows the TC of liquid Sodium with Silver nanoparticles as a component of nanoparticle application between $1 \%$ and $8 \%$. The TC of Silver nanofluids rises in lockstep with the nanoparticle concentration [36].

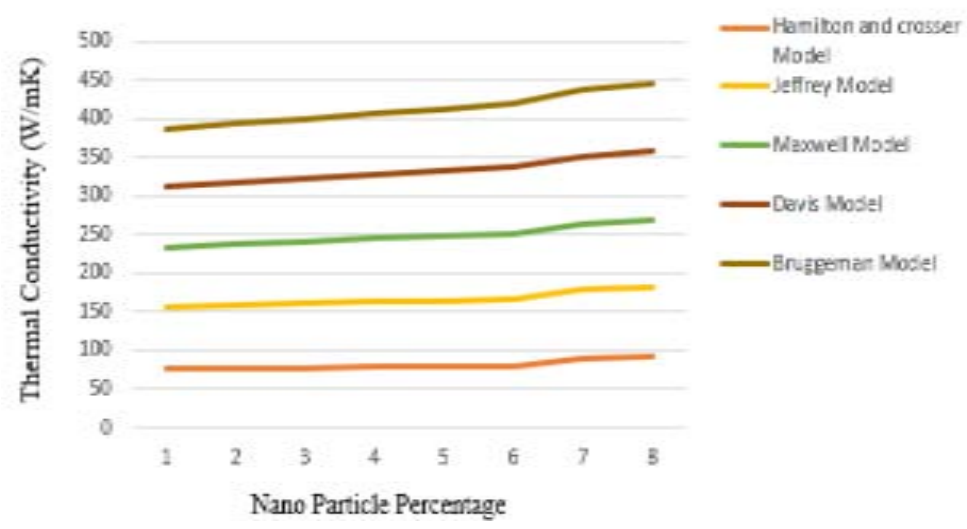

Figure 10. Thermal Conductivity of Nanofluids (Silver + Liquid Sodium).

The TC of Sodium with 1-8 percent Copper nanoparticles is presented in Table 9, along with a judgment of outcome utilizing theoretical TC models [37].

Table 9. TC of nanofluids (Liquid Sodium + Copper)

\begin{tabular}{|c|c|c|c|c|c|}
\hline $\begin{array}{c}\text { Nano } \\
\text { Particle } \\
\text { percentage }\end{array}$ & $\begin{array}{c}\text { Hamilton } \\
\text { and Crosser } \\
\text { Model }\end{array}$ & $\begin{array}{c}\text { Jeffrey } \\
\text { Model }\end{array}$ & $\begin{array}{c}\text { Maxwell } \\
\text { Model }\end{array}$ & $\begin{array}{c}\text { Davis } \\
\text { Model }\end{array}$ & $\begin{array}{c}\text { Bruggeman } \\
\text { Model }\end{array}$ \\
\hline 1 & 77.346 & 79.98 & 77.346 & 77.3597 & 74.852 \\
\hline 2 & 78.708 & 81.37 & 78.7083 & 78.7635 & 76.381 \\
\hline 3 & 80.086 & 82.76 & 80.0867 & 80.2130 & 77.944 \\
\hline 4 & 81.481 & 84.23 & 81.4817 & 81.7097 & 79.543 \\
\hline 5 & 82.893 & 85.70 & 82.8936 & 83.2555 & 81.179 \\
\hline 6 & 84.322 & 87.21 & 84.3226 & 84.8519 & 82.852 \\
\hline 7 & 85.769 & 88.75 & 85.7692 & 86.5009 & 84.563 \\
\hline 8 & 87.233 & 90.31 & 87.2335 & 88.2041 & 86.312 \\
\hline
\end{tabular}


Copper nanoparticles have a TC of $400 \mathrm{~W} / \mathrm{mK}$, whereas liquid sodium has a TC of $76 \mathrm{~W} / \mathrm{mK}$ at ambient temperature. Table 9 shows the TC of liquid Sodium incorporating Copper nanoparticles as a nanoparticle focus element between 1-8\%. Copper nanofluids’ TC rises in lockstep with nanoparticle fixation.

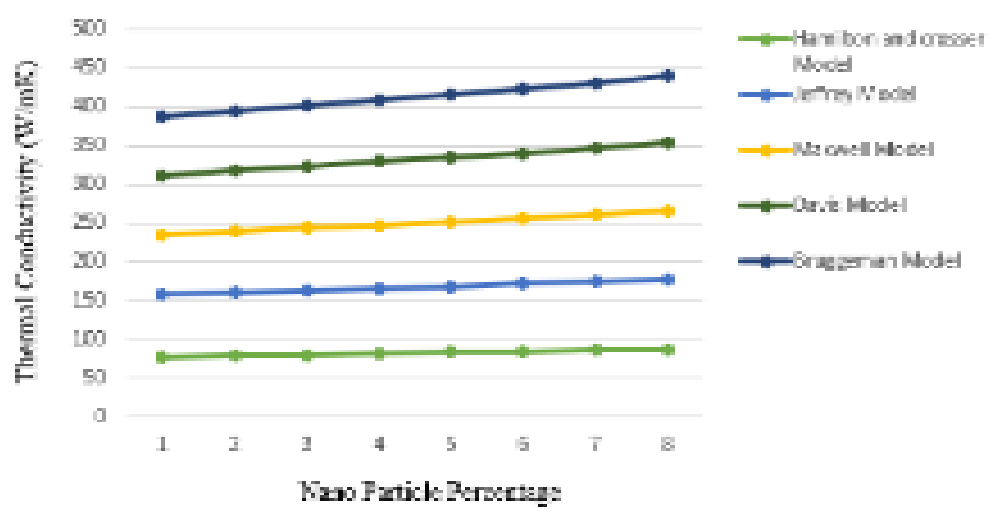

Figure 11. Thermal Conductivity of Nanofluids (Copper+ Liquid Sodium).

\section{Conclusion}

The findings suggest that nanofluids containing modest concentrations of nanoparticles have significantly greater heat conductivity than basic liquids. The amount of molecule volume, the dimension and condition of nanoparticles, the kind of base liquid and nanoparticles, the $\mathrm{pH}$ value of nanoliquids, and the TC of nanofluids is affected by the sort of molecule that covers them all. The most accurate model for nanofluid TC is currently lacking. It is clear from the preceding graphs and tables that the Maxwell model exhibits some common variations in comparison to other models. Suresh and Davis models have greater TC values, Suresh's model, alternatively, has a much greater TC value than the other models. In comparison to Suresh and Davis models, the Bruggeman model provides slightly higher TC. The Hamilton and Crosser models are more similar to the Jeffrey model in terms of attributes.

\section{References}

[1] K. Abdul Hamida, W. H. Azmia, M. F. Nabila, and Rizalman Mamatb. (2019). "Viscosity determination of titanium dioxide in water and ethylene glycol mixture based nanofluid.” Indian Journal of Pure \& Applied Physics, vol. 57, pp. 461-465, 2019.

[2] Y. H. Kwon, D. Kim, C. G. Li, J. K. Lee, D. S. Hong, J. G. Lee, S. H. Lee, Y. H. Cho, and S. H. Kim. (2011). "Heat Transfer and Pressure Drop Characteristics of Nanofluids in a Plate Heat Exchanger.” Journal of Nanoscience and Nanotechnology, vol. 11, pp. 5769-5774, 2011.

[3] Wahaizad Safiei, Md Mustafizur Rahman, Ratnakar Kulkarni, Md Noor Ariffin, Zetty Akhtar Abd Malek. (2020). "Thermal Conductivity and Dynamic Viscosity of Nanofluids: A Review." Journal of Advanced Research in Fluid Mechanics and Thermal Sciences, vol. 74, no. 2, pp. 66-84 , 2020.

[4] Mehta, S., Chauhan, K. P., and Kanagaraj, S. (2010). "Modeling of thermal conductivity of nanofluids by modifying Maxwell’s equation using cell model approach.” Journal of Nanoparticle Research, vol. 13, pp. 2791-2798, 2010.

[5] Osato Miyawaki and Rungnaphar Pongsawatmanit. (1994). "Mathematical Analysis of the Effective Thermal Conductivity of Food Materials in the Frozen State.” Biosci. Biotech. Biochem, vol. 58, no. 7, pp. 1222-1225, 1994.

[6] R. A. Arul Raja and J. Sunil. "Estimation of Thermal Conductivity of Nanofluids Using Theoretical Correlations." International Journal of Applied Engineering Research, vol. 13, no. 10, pp. 7932-7936, 2018.

[7] Kewen Li, Dan Wang, and Shanshan Jiang. (2018). "Review on enhanced oil recovery by nandfuids ." Oil \& Gas Science and Technology, vol. 73, no. 37, 2018.

[8] Mohammadhassan Vasheghani, Ehsan Marzbanrad, Cyrus Zamani, Mohamed Aminy, and Babak Raissi. (2013). "Thermal Conductivity and Viscosity of Tio2-Engine Oil Nanofluids.” Nanomechanics Science and Technology, vol. 4, no. 2, pp. 145-156, 2013.

[9] Ahmad Amiri, Mehdi Shanbedi, and Mohammad Javad AliAkbarzade. (2016). "The Specific Heat Capacity, Effective Thermal Conductivity, Density, and Viscosity of Coolants Containing Carboxylic Acid Functionalized Mul- 
ti-Walled Carbon Nanotubes.” Journal of Dispersion Science and Technology, vol. 37, pp. 949-955, 2016.

[10] V. Rudyak. (2018). "Modeling of Nanofluid Flows. Problems, Methods, Results.” In AIP Conference Proceedings, Russia , 2018.

[11] Vladkov, M. and J. Barrat. (2006). "Modeling thermal conductivity and collective effects in a simple nanofluid.” In $H A L$, France, 2006.

[12] H. A. Houda Jalali. (2016). "Evaluation of Heat Transfer and Entropy Generation by Al2O3-Water Nanofluid.” International Journal of Mechanical and Mechatronics Engineering, vol. 10, no. 12, pp. 1900-1907, 2016.

[13] V. Rudyak. (2018). "Modeling of Nanofluid Flows. Problems, Methods, Results.” In International Conference on the Methods of Aerophysical Research, Russia, 2018.

[14] Lalit B. Chintamani and N. C. Ghuge. "A Review Paper on Experimental Heat Transfer Enhancement using Nanofluids.” International Journal of Innovative Research in Advanced Engineering, vol. 2, no. 2, pp. 64-67, 2015.

[15] Nandkumar Sadashiv Vele and R. K. Patil. (2019). "Review On Heat Transfer Enhancement In Car Radiator Using Nano Fluid.” In Proceedings of the International Conference on Industrial Engineering and Operations Management, Bangkok, 2019.

[16] Rajashekhar Pendyala, Jia Ling Chong, and Suhaib Umer Ilyas. (2015). "CFD Analysis of Heat Transfer Performance in a Car Radiator with Nanofluids as Coolants.” CHEMICAL ENGINEERING TRANSACTIONS, vol. 45, pp. 1261-1266, 2015.

[17] Wayan Nata Septiadi, Ida Ayu Nyoman Titin Trisnadewi, Nandy Putra, and Iwan Setyawan. (2018). "Synthesis of hybrid nanofluid with two-step method.” In E3S Web of Conferences, 2018.

[18] S. Parvin, R. Nasrin, M. A. Alim, and N. F. Hossain. (2013). "Effect of Prandtl Number on Forced Convection in a Two Sided Open Enclosure Using Nanofluid.” JOURNAL OF SCIENTIFIC RESEARCH, vol. 5, no. 1, pp. 67-75, 2013.

[19] Nayara Rodrigues, Douglas Hector Fontes, and Enio Pedone Bandarra Filho. (2015). "A Review on Application of Nanofluid as Coolant in Automotive Cooling System.” International Journal of Mechanical and Production Engineering, no. 1, pp. 14-19, 2015.

[20] R. E. White. (2003). Computational Modeling with Methods and Analysis, North Carolina: CRC Press, 2003.

[21] Shubham Sharma, Arun Kumar Tiwari, Sandeep Tiwari, Ravi Prakash. (2019). "Particle Optimization of Ceo2/Water Nanofluids in Flat Plate Solar Collector.” International Journal of Engineering and Advanced Technology, vol. 9, no. 2, pp. 1467-1474, 2019.

[22] Rahul A. Bhogare and B. S. Kothawale. (2013). "A Review on applications and challenges of Nano-fluids as coolant in Automobile Radiator.” International Journal of Scientific and Research Publications, vol. 3, no. 8, 2013.

[23] Mushtaq I. Hasan, Abdul Muhsin A. Rageb Rageb, and Mahmmod Yaghoubi. (2012). "Investigation of a Counter Flow Microchannel Heat Exchanger Performance with Using Nanofluid as a Coolant.” Journal of Electronics Cooling and Thermal Control, vol. 2, pp. 35-43, 2012.

[24] N. Ramakoteswara Rao, L. Gahane, and S. V. Ranganayakulu. (2017). "Acoustical and thermal conductivity study of Ag nanofluids.” International Journal of Research in Pharmaceutical Sciences, vol. 8, no. 4, pp. 767-771, 2017.

[25] A. L. Subramaniyan and R. Ilangovan. (2015). "A report on the latest trends in nanofluid research.” International Journal of Nano Dimension, vol. 6, no. 3, pp. 323-328, 2015.

[26] Gloria A. Adewumi, Freddie Inambao, Mohsen Sharifpurb, and Josua P. Meyer. (2018). "Investigation of the Viscosity and Stability of Green Nanofluids from Coconut Fibre Carbon Nanoparticles: Effect of Temperature and Mass Fraction.” International Journal of Applied Engineering Research, vol. 13, no. 10, pp. 8336-8342, 2018.

[27] Sayantan Mukherjee and Somjit Paria. (2013). "Preparation and Stability of Nanofluids—A Review.” IOSR Journal of Mechanical and Civil Engineering, vol. 9, no. 2, pp. 63-69, 2013.

[28] E. Germaine, L. Mydlarski, and L. Cortelezzi. (2014). "Evolution of the scalar dissipation rate downstream of a concentrated line source in turbulent channel flow.” J. Fluid Mech, vol. 749, pp. 227-274, 2014.

[29] Purna Chandra Mishra, Sayantan Mukherjee, Santosh Kumar Nayak, and Arabind Panda. (2014). "A brief review on viscosity of nanofluids.” Springer, vol. 4, pp. 109-120, 2014.

[30] S. V. Nikkhah. (2019). "Thermal performance of a micro heat exchanger (MHE) working with zirconia-based na- 
nofluids for industrial cooling.” International Journal of Industrial Chemistry, vol. 10, pp. 193-204, 2019.

[31] Navid Bozorgan, Komalangan Krishnakumar, and Nariman Bozorgan. (2012). "Numerical Study on Application of CuO-Water Nanofluid in Automotive Diesel Engine Radiator.” Modern Mechanical Engineering, vol. 2, pp. 130-136, 2012.

[32] W. N. Mutuku. (2016). "Ethylene glycol (EG)-based nanofluids as a coolant for automotive radiator.” Mutuku Asia Pac. J. Comput. Engin, vol. 3, no. 1, 2016.

[33] Tiwari Arun Kumar, Ghosh Pradyumna, and Sarkar Jahar. (2012). "Investigation of Thermal Conductivity and Viscosity of Nanofluids.” Journal of Environmental Research and Development, vol. 7, no. 2, pp. 768-777, 2012.

[34] N. K. Chavda. (2015). "Effect of Nanofluid on Heat Transfer Characteristics of Double Pipe Heat Exchanger: Part-Ii: Effect of Copper Oxide Nanofluid.” International Journal of Research in Engineering and Technology, vol. 4, no. 4, pp. 668-696, 2015.

[35] Rohit S. Khedkar, Shriram S. Sonawane, and Kailas L.Wasewar. (2012). "Water to Nanofluids heat transfer in concentric tube heat exchanger: Experimental study.” In Chemical, Civil and Mechanical Engineering Tracks of 3rd Nirma University International Conference on Engineering, 2012.

[36] A. Gakare. (2019). “A Review on Nanofluids: Preparation and Applications.” A Journal of Nanotechnology and Its Applications, vol. 21, no. 1, pp. 21-35, 2019.

[37] Cheen Sean Oon, Sin Nee Yew, Bee Teng Chew, Kazi Md Salim Newaz, Ahmed Al-Shamma'a, Andy Shaw, and Ahmad Amiri. (2015). "Numerical simulation of heat transfer to separation tio2/water nanofluids flow in an asymmetric abrupt expansion.” In EPJ Web of Conferences, Malaysia, 2015. 